\title{
Examining the Impact Information Communication Technology (ICT) Has on Adolescents with Disabilities
}

\author{
Ibrahim F. Baig
}

\begin{abstract}
Information Communication Technology (ICT) is widely viewed as playing an integral part in the lives of students and fundamental to the progress of current education systems and the development of 21st century skills. Assistive technology has given children with learning disabilities and their parents great hope of participation, mutuality and equal opportunities mirroring inclusive classroom practices. Therefore, this research study examined the impact Apple iPad technology has on fostering new learning opportunities for young adolescents with disabilities specifically in regards to learning engagement and independent educational opportunities as viewed by two special education teachers.
\end{abstract}

Index Terms-Information communication technology, assistive technology, iPad, teacher training.

\section{INTRODUCTION}

In an era that is defined by innovation, considering existing scholarship around technology, [1], a leading scholar in technological determinism, developed the extension theory where he states, "...technical objects are conceived of as some kind of extension of human organism by way of replicating, amplifying, or supplementing bodily or mental faculties or capabilities", which has helped our understanding of the role of technology towards extending our abilities. Educators and stakeholders are finding that ICT is the way of the future, making the investment in tablet devices a great choice [2], as many school boards are finding that these mobile devices are the tools to fulfill their instructional needs [3]. Teachers working with non-verbal students at Beverley Public School in Ontario, Canada found that autistic students achieved at levels that even the children's parents had no idea they were capable of [4]. On a similar note, a pilot study conducted to be published [5] asked staff members to rate student performance and engagement during reading and math instruction while the iPad was an active part. They found that in a classroom environment where iPads and iPods were employed, as opposed to traditional classroom tools, students with disabilities engaged in "appropriate behavior for a greater percentage of time, demonstrated increased accuracy in performing the task, showed more interest and motivation in the instruction, and demonstrated increased independence with less adult support". A clear indication of the positive impact technology can have in the classroom for various aspects of learning. As a result, the time could not be better to

Manuscript received April 20, 2013; revised June 30, 2013.

Ibrahim F. Baig is with the Ontario Institute for Studies in Education, University of Toronto (e-mail: Ibrahim.baig@gmail.com). examine and explore how Apple iPad technology can alleviate barriers for students who may suffer from learning disabilities as they search for new opportunities to engage in profound experiences.

\section{KEY QUESTIONS}

The following questions served as the foundation for the inquiry as iPad technology within educational settings were explored: a) How and in what ways are the iPad and relevant applications capable of fostering learning opportunities for both the teacher of students with disabilities and their students? b) How do/do not iPads and relevant applications impact aspects of independence and engagement for students with disabilities as viewed by special education teachers? Investigating a model of learning that helps educators move beyond a "one size fits all" mode of instruction while maximizing the educational benefits for all students is the premise of my inquiry.

With that said, these questions are essential to the project because as [6] mention, there are three areas in which educators have found assistive technology to be lacking: a) higher order thinking skills do not appear to be adequately incorporated, b) software is not well-grounded in educational research and pedagogy, and (c) the range of skill levels required to meet the needs of individual students is often not included. Exploring instructional practices that employ multimodality, and discovering bridges to meaningful engagement that reduces barriers at the outset of the learning process are key aspects of this research study.

\section{THEORETICAL FRAMEWORK}

This research study was examined through phenomenology, which sets the framework for meaning, structure, and essence of the lived experience for a person or group of people [7]. Implementing phenomenology as the fabric of this study presented a chance to yield detailed information from teachers whose students with disabilities used an iPad. As phenomenology focuses on how "human beings make sense of experience and transform experience into consciousness" [7], capturing and considering the observations of the teacher's through their feelings and understandings extended the opportunity to examine how iPad technology could positively or negatively influence learning.

In addition, the use of disability theory particularly one that focused on the social-model, frames how socially constructed barriers present hurdles for students with 
impairments through systematic obstacles, negative attitudes and exclusion by society. Reference [8] describes that the social model of disability serves as a way of understanding how people with impairments are disabled by the fact that they are excluded from participation as a result of physical, organizational and attitudinal barriers.

These two theoretical frameworks compliment one another as they promote a reflexive consideration of the experience of students with disability and develop an understanding of the ways in which barriers imposed limited learning opportunities. As a result, throughout this paper, [sic] has been placed beside the word 'special' when referring to special education in various quotes and references. With language an important aspect of disability, the word 'special' is filled with a number of connotations that place students with disabilities in a category of their own and this researcher would like to ensure that the term 'special' is not supported in any manner; the correct terminology is students with disabilities.

\section{Methods AND PROCEDURE}

This qualitative research project spanned four weeks and took place at one high school with two teachers in the Developmentally Delayed Special [sic] Needs Program. Three interview dates were established, prior, during and after the research period, alongside the e-mail reflections throughout to round off the set of observations; a total of 14 email reflections were collected from both teacher participants alongside.

\section{A. Workshop and Interviews}

A professional development workshop was arranged, which was the same date as the pre-research interview. The workshop lasted approximately one hour as both teachers were introduced to the researcher and enabled participants to grasp the purpose of the study, their involvement regarding interviews and use of the iPads that were to be integrated throughout an upcoming unit or lessons. As the workshop concluded, "semi-structured" interviews ensued with a range of questions that asked: Tell me about your career as a special education teacher? What is your opinion about the research study? How would you describe your physical classroom environment? What is your personal experience with technology? By the end of these initial interviews there was an obvious excitement in the voices of both teachers, they were eager to begin integrating the iPads into their classroom environments.

With the other two interviews seeking to answer a wide range of questions, the former addressed the program structure and initial iPad use and included questions such as: In your opinion, how is the use of iPads in your classroom coming along? Are there any challenges? How would you describe your classroom environment when the iPad is being used for instruction/activities? How has the iPad fostered new learning opportunities for you as a teacher? What are your goals for the final few weeks? Whereas the latter interview after the study entailed questions such as: How would you describe your classroom environment when the iPad is being used for instruction/activities? How has the
iPad fostered new learning opportunities for you as a teacher? And for the students? What are a few observations that stand out in contrast to before when traditional tools were being used? What are your goals for the final few weeks?

\section{About The Teachers AND PROGRAm}

The research participants for this four-week study were Mrs. Williams ${ }^{1}$ who is in her first year of teaching in the developmentally delayed program after teaching the previous four years in special education at the same school, and $\mathrm{Mr}$. Crawford ${ }^{1}$, who is in his seventh year in the developmentally delayed program and who is responsible for starting the intensive needs program during his first year as a teacher at this school.

Regarding her personal use of technology, Mrs. Williams felt she is in-tune with technology using her smartphone on a daily basis and "wouldn't be able to live without it". She believed "a combination of attitudinal barriers, financial barriers alongside a lack of adequate and relevant training" has limited the opportunity for the program to reach its full potential. Mrs. Williams appeared to be clearly interested in the individualization that technology provides towards filling the gaps students bring with them into the developmentally delayed program.

At Mr. Crawford's first and only position at his current school, he was asked to develop the DD program due to the increasing need for classes that primarily focused on the life skills of students. When informed about the research study, Mr. Crawford stated that he was prompted "by the opportunity to use technology in the classroom". Since he was not familiar with iPads at all, in the class or for personal use, the research goals sounded great to him and he was looking forward to using the iPads to determine whether technology is the "be all end all" it is often made out to be. With respect to his personal use of technology, Mr. Crawford is not "technologically savvy" as he put it, with only basic computer skills such as email and a cell phone that is only used for calling as opposed to a smartphone for emailing and applications. His outlook on education, which was reflected in the apps he chose to have downloaded on the iPad devices, is that students in the DD program should be taught in a manner that is applicable to their lives. He asked, "Can technology help with that?"

\section{A. Program Structure}

Mrs. Williams outlined that the DD program is intensive. It is "self-contained" which meant that all students are in one classroom throughout the day with a few teachers in and out. There are various subjects throughout the day but the permeating theme is the development of life skills. As the interview steered towards the difference for teachers in this program and 'regular' special [sic] education, Mrs. Williams mentioned that "in special [sic] education there is extended resource support; come into a classroom and support the students". Whereas, "the DD program works off a specific curriculum and courses called ' $\mathrm{K}$ courses' that are non-credit which include life skills and functional academic work.

\footnotetext{
${ }^{1}$ Name of teacher participants was changed.
} 
Regarding the demographics of the DD program, each student is allowed to be there until the age of 21 , although students generally range from 14-18. With respect to their academic levels, they are working at levels anywhere from kindergarten to grade three. This applied to all students where the highest level of achievement is grade three. Students are grouped by ability and each class size has a maximum of 5 to 7 students. Students in the DD program used to receive the same report card as students as the mainstream program but this has changed in the past two years. Describing those changes, Mrs. Williams pointed out "Report cards are not anecdotal and now there is a lot more qualitative description about what students are doing; this is much better for parents as it facilitates communication and understanding about where their child is functioning". Further, Mrs. Williams described that a student graduates from the DD program when he or she has "acquired adequate life skills and receives a certificate of achievement". Therefore, the goal of this program is that students leave with skills that are applicable to what they do in and outside of school.

\section{ANALYSIS}

To develop an understanding of the learning that took place for students with disabilities, connecting the observations from each participant to current literature developed opportunities for future implications in classrooms for both students and teachers.

\section{A. Fostering New Learning Opportunities}

The ability to examine whether or not the iPads were able to foster new learning opportunities for both the teacher and students was aided by the detailed interviews and email reflections. In the initial interview, Mrs. Williams mentioned, "The manner in which the iPads have become a part of the daily routine is pleasing". With respect to the iPads fostering new learning opportunities for herself and her students, she mentioned that when iPads are being used in the classroom "it's not necessary to stop the class since students can move right along as they complete their work...students know how to use the devices so they can work alone". Similar literature found that "technology in the classroom improves student outcomes as teachers continue to integrate technological tools into the learning and teaching experience" [9]. Further, her class was able to work with grade 10 students in the cafeteria using the WiFi network through an activity known as "parallel play"; students worked with one another without influencing one another's behaviour using the iPad, which tailed off into other exercises using the iPad where students would be responsible for describing the emotion she, the teacher, acted out on the iPad which certainly demonstrated the flexible learning opportunities.

Towards the end of the research study, Mrs. Williams described an activity which was enabled by her exploration of applications. She wrote, "I downloaded a c-fit app that showed videos and step by steps of different exercises. It was really good. Students worked in pairs and chose an exercise from each section to learn and then demonstrated it to their classmates. It was a good mini exercise". These types of activities are reflected in the research as the unique features of iPads were addressed by [10] that stated "applications which that use multi-gesture features allow disabled students with different levels to learn simultaneously and to achieve multiple different learning purposes" (pp. 531) and mirror other results in current research where the iPad has been found to be "an idea assistive technology tool that provides a platform to engage its users and help them success in many situations" [11].

As for Mr. Crawford, he mentioned that the iPads are "progressing and students are having fun as the iPad transitions from being viewed as a "toy" to being viewed as a "tool". When discussed the manner in which iPads have fostered learning opportunities for him as a teacher and his students, he mentioned that "there are good options for mixed learning, as we can take a break from some work and get back to other things, which presents a break for me as a teacher and for the students as well". On the same note, he strongly emphasized that the iPads can be a "tool to assist learning not replace it" but considered it a "good medium ground". The opportunity for him as a teacher to focus more on the task his students were able to navigate through the application was beneficial.

Considering the iPad as a tool that fostered new learning opportunities for teachers of special with disabilities and for students themselves, the feeling from each teacher was that the device's flexibility made the prospect of trying new things easier and more manageable. As for fostering new learning opportunities for the participants, the permeating theme expressed by both teachers that was due in part to the sheer volume of applications and options that were available; trying new things was plausible and being flexible in the differentiated learning settings and activities was realistic. Upon further examination, each teacher found that the various applications could supplement a variety of learners; in the case of Mrs. Williams it was new communication methods for her autistic students alongside physical activity exercises and for Mr. Crawford it was the ability for his students to spend more time working effectively.

\section{B. Independence}

One of the key questions this research study sought to answer is whether iPads could impact aspects of independence for students with disabilities. By providing this level of analysis, further insight may be gained into how these tools can enrich schooling and learning experiences. When discussing independence, Mrs. Williams stated "students are able to work alone as they can navigate through the iPads without any issues" and found that on the first day of iPad use "students were fairly independent and intuitively seemed to know what to do to make things happen on the iPad", this is interesting as there did not appear to be much of a learning curve which could have been due to previous exposure to the iPad or the easy nature the device is founded upon; "the iPad is an ideal assistive technological tool that provides a platform to engage its user and help them succeed in many situations" [11].

Towards the latter part of the research period Mrs. Williams wrote, "It worked well. Students were able to work with each other and socialize with others they don't normally 
do". I was struck by this comment as it revealed that these students, being autistic and non-communicative to some extent, must have found alternative methods of getting the message across. While this is an indication that the iPads promoted independence in the classroom with respect to students' learning, in some light this could also be looked upon as a new way for autistic students to communicate with one another, essential in today's dynamic school setting. It is apparent that during the four weeks, Mrs. Williams' students were able to observe aspects of independence through the iPad which resulted in individualized learning opportunities subsequently impacting their learning.

In the case of Mr. Crawford, during his interview midway the research study, he was unable to clearly determine if the devices had facilitated independent learning opportunities for his students. Rather, as he mentioned in the second interview, "their ability to get the iPads from the office and bring them to the classroom on their own in some light can be viewed as an act of independence". However, in the days to come he followed that up with, "majority of students are able to find their way around the iPad functions after repeated support and now are own their way to working independently". After the initial hurdles, it appears his students became independent with the devices with consistent support from their teacher.

In his final interview. Mr. Crawford reflected on his initial statement, which said that he was "skeptical" about the actual impact the iPads could have on his students; he still felt this way. With that being said, the interviews and email reflections from Mr. Crawford appear to have enabled a unique experience from his students but not enough of one for him to have them to work along for an extended period of time and considering the iPad as a tool that fostered new learning opportunities for teachers of special with disabilities and for students themselves, the feeling from each teacher was that with more time it would be likely students will become more independent and increase their ability to work in a student-centered environment. With current literature continuing to report similar results, this research opportunity was a great chance to witness how the iPad can positively impact aspects of independence as viewed by two special education teachers and the role of the teacher towards adaptability of the students towards new technological devices.

\section{Engagement}

The latter question this research study sought to answer is whether or not iPads impacted learning engagement. This focused analysis presented an interesting prospect towards investigating how up-to-date technology played an influential role in the classroom for students with disabilities. In her observation of her students' use of iPads, Mrs. Williams mentioned "There is absolutely no issue. Positive results as they [the students] are always on task and are interested in the working on various apps even a few weeks in [after the excitement has settled]". This is an interesting comment because as [3] reports, schools are trying to find a new way to study students that is relative to their level and interesting yet engaging; "tablets are the newest thing", which speaks to the interest that has been sustained by Mrs.
Williams' students. She goes on to mention that "the flexibility of knowing the students are engaged with the iPads has allowed for it to become seamlessly a part of daily lessons". Looking back on the four weeks she reflected on learning engagement and said that, "They were engaged from day one. They were interested everyday about what we were going to do with them. Students had their own which was great". Mrs. Williams demonstrated throughout her observations that the iPad had the capability to positively impact learning engagement for students with disabilities as a result of her deep reflections that paid close attention to how these devices impacted her students' learning environment.

Mr. Crawford had little to say about learning engagement other than the fact that "the iPad is fun" as his students explored the device to become acquainted with them. He noted that "some of them [students] want a break from the iPad, not sure if they are tired or if they want a break to do something else". In his latter observations he said, "All students were very excited about having the opportunity to use the iPad. The camera/photo booth was extremely popular with the variety of pictures that can be taken. Most students explored all the apps". Similar observations by [2] found that "iPads provide better access to participation in learning and engagement, and it's proven to be doing that". The subsequent reflections by Mr. Crawford indicated that, "Student engagement continues to be high". When considering the range of observations made by Mr. Crawford, his initial forecast stated, "Students will be excited to use a new piece of technology that might engage them for a short while", but his confidence in using the iPads and its long-terms effects are not similar to views expressed by Mrs. Williams. Mr. Crawford saw the possibility for learning engagement to increase, but suggested the iPad was a tool in the classroom that had its window of opportunity, once that chance surpassed then it was time to move on. Nevertheless, the observations from Mr. Crawford shed light on the potential benefits of iPad technology in the classroom for students with disabilities regarding their learning engagement. With his students experiencing an extended learning curve it might be in the best interest for future research to take place over an entire school year with examination of how the teacher could influence students when using the devices. With Mr. Crawford interested in working on the development of social skills of his students, current literature found that the collaboration between technology and social skills instruction had positive results as [12] reports, "Incorporating technology into social skills training can be effective and a form of motivation". However, in the same report [12] indicated "If the teacher is not technology savvy, he or she will need to take the time to learn how to use the required technology for these [types] of lessons". It is interesting to note that in Mrs. Williams' class the iPads were used for diverse array of subjects with differentiated learning being a key component, whereas for Mr. Crawford, iPads were predominantly used for math related concepts. The use of iPads for differentiated purposes and subjects could have influenced the varying degrees engagement that was experienced by the students of each teacher. 


\section{FINAL THOUGHTS}

Exploring an educational technology and facilitating future discussions by documenting the perspective of two special education teachers on the use of iPads for students with disabilities was a rewarding experience. This research study provided an opportunity to determine how iPads can foster new learning opportunities for teachers of special education students and for students themselves. The detailed observations reported by both teachers found increased differentiated instruction opportunities, which is essential to the development of their students

This research study sought to determine whether or not the iPad would impact the main aspects of learning, namely independence and engagement. It was apparent that the iPad enabled independent learning opportunities for students. Due in part to their engagement with the device, students in both classes were able to increase the amount of time they would work alone or in various group settings without requiring teacher intervention. This, as Mrs. Williams and $\mathrm{Mr}$. Crawford both mentioned, was a great chance for their students to ask more questions and have additional time to explore a device they did not usually have access to. The end result from both teachers' observations was a positive inclination towards the manner in which iPads were able to foster independent learning channels for their students.

As for the aspect of learning engagement, it was overwhelmingly clear that the iPads were able to sustain the interest of the students. To some extent this was expected as both teachers forecasted such results and current literature sites similar observations, but nevertheless this was an opportunity for the teachers to experience this engagement first hand. This experience provided the teachers with a new perspective on up-to-date technology and the end result was that both teachers found the iPad had a significant impact on the students' learning engagement, which allowed them to explore flexible learning methods in their classrooms.

The final results of this research study shed positive light regarding the use of iPads in classrooms for students with disabilities. This signifies a positive step towards developing an understanding of this educational tool as a medium for disadvantaged adolescents. If the opportunity arose to further this research study I would see great benefit in lengthening the research study period in order to more richly expound on the observations and results especially towards considering aspects of achievement. It would be interesting to spend time in the classroom as a participant observer while understanding students, their tendencies and their disabilities. Determining whether or not they had achieved a measure amount of success in any given area would them become easier to examine with more time to consider how they performed before and after the technological device was added or removed from their learning environment. As for the methods, the email reflections were highly effective for Mrs. Williams and would be a definite asset in any future research opportunities alongside interviewing parents. By engaging with iPad devices as a form of assistive technology, my research on the needs of students with disabilities has hopefully built on previous research while embarking on new topics; all with the aim towards helping vulnerable students meet their full academic and socio-cultural potential.

\section{REFERENCES}

[1] C. Lawson, "Technology and the extension of human capabilities," Journal for the Theory of Social Behaviour, vol. 40, pp. 207-223, 2010

[2] K. Dyett, "School gadgets boost student communication," $A B C$ (Australian Broadcasting Corporation) News, Jan $5^{\text {th }} 2012$

[3] J. Roland, "Educators Reveal Why (and How) School Districts Are Adopting Tablets," EDTECH: Focus on K-12, Jan $7^{\text {th }} 2013$.

[4] K. Rushowy, "The autism project: Groundbreaking iPad research earns two Toronto teachers Prime Minister's awards," The Toronto Star, Nov. $12^{\text {th }} 2012$.

[5] C. D. L. Cruz, "iTechnology pilot study outcomes," Northern Suburban Special Education District, Illinois, United States, 2011.

[6] R. Boone and K. Higgins, "New directions in research: The role of instructional design in assistive technology research and development," Reading Research Quarterly, vol. 42, no. 1, pp. 135, 2007.

[7] M. Q. Patton, Qualitative research and evaluation methods, $3^{\text {rd }}$ ed., London, 2002.

[8] G. Carson, "The social model of disability," Scottish Accessible Information Forum (SAIF), Scotland, 2009

[9] R. Bonnstetter and D. VanOverbeke, “APP'lications for mobile computing in K-12 and pre-service education," in Proc. Society for Information Technology and Teacher Education International Conference 2012, Chesapeake, VA: AACE, pp. 3428-3433.

[10] L. L. Chen, "Integrating iPad in a special education class: A case study," in Proc. World Conference on E-Learning in Corporate, Government, Healthcare, and Higher Education 2012, Chesapeake, VA: AACE, pp. 530-534.

[11] J. Conley, "Can the iPad address the needs of students with cognitive impairments by meeting IEP goals?" in Proc. Society for Information Technology and Teacher Education International Conference 2012, Chesapeake, VA: AACE, pp. 3986-3990.

[12] T. Cumming, "Using technology to create motivating social skills lessons," Intervention in School and Clinic, vol. 45, no. 4, pp. 242-250, Hammil Institute on Disabilities, 2010.

Ibrahim F. Baig was born in Toronto, Ontario, Canada. He is a $\mathrm{Ph} . \mathrm{D}$ (Candidate) University of Toronto: Ontario Institute of Studies in Education. He obtained his M.Ed, B.Ed and B.A, York University. He is majored in recipient of social sciences and humanities research.

$\mathrm{He}$ joined in Council of Canada: Joseph-Armand Bombardier Canada Graduate Scholarship (CGS). His current research focuses on the impact tablet technology, such as iPads, has on young adolescents with special needs regarding the nature of learning engagements and inclusive educational opportunities within classrooms and $21^{\text {st }}$ century skill development practices. 